\title{
The Prevalence of Burnout and Its Association With Types of Capital Among Female Nurses in West of Iran
}

\author{
Behzad Karami Matin ${ }^{1}$; Sina Ahmadi ${ }^{2}$; Sayed Fahim Irandoost ${ }^{3}$; Nafe Babasafari ${ }^{4}$; Satar \\ Rezaei $^{1, *}$ \\ ${ }^{1}$ Department of Public Health, School of Health, Kermanshah University of Medical Sciences, Kermanshah, IR Iran \\ ${ }^{2}$ Department of Social Welfare, University of Social Welfare and Rehabilitation Sciences, Tehran, IR Iran \\ ${ }^{3}$ Department of Sociology, University of Kurdistan, Sanandaj, IR Iran \\ 4 Department of Sociology, University of Tehran, Tehran, IR Iran \\ *Corresponding author: Satar Rezaei, Department of Public Health, School of Health, Kermanshah University of Medical Sciences, Kermanshah, IR Iran. Tel: +98-9181324024, Fax: +98- \\ 8318263048, E-mail: satarrezaei@gmail.com.
}

Received: April 6, 2014; Revised: May 4, 2014; Accepted: May 11, 2014

\begin{abstract}
Background: Burnout is a common syndrome associated with job stresses in the health sector personnel, especially female nurses. Objectives: The aim of this study was to investigate burnout and its association with types of capital among female nurses in educational hospitals of Kermanshah University of Medical Sciences.

Patients and Methods: This was a retrospective cross-sectional study. The study population was all female nurses working in educational hospitals of Kermanshah University of Medical Sciences. Participants completed a questionnaire containing three parts as: Maslach Burnout Inventory, the types of capital and sociodemographic characteristics. Data Analysis was done using SPSS version 18.

Results: In total, $40 \%$ of female nurses had a high level of burnout. The mean scores of the emotion exhaustion, depersonalization and personal accomplishment were 33.7,16 and 25.7, respectively. In addition, 50\% of female nurses had a high social capital, $86 \%$ of them had a moderate economic capital and $49.3 \%$ had a low cultural capital. Finally, there were significant negative correlations between burnout and capital types (economic, cultural and social).

Conclusions: The prevalence of burnout among nurses is high. Capital types had a positive impact on reducing burnout. Therefore,
\end{abstract} maintaining capital types should be considered to decrease burnout in nurses.

Keywords:Prevalence; Female; Nurses

\section{Background}

Occupation is one of the main resources of stress. Studies have shown that approximately $75 \%$ of Americans experience degrees of occupational stress and job efficiency of a half of them is decreased due to stress. Burnout is a consequence of long-term stress $(1,2)$. Burnout was first developed by the psychologist Freudenberg Herbert in 1970 with three subscales of emotional exhaustion (EE), depersonalization (DP) and personal accomplishment (PA) $(3,4)$. Burnout can lead to inappropriate physical and psychological consequences such as depression, decreased job satisfaction and performance, increasing family problems, absenteeism from work and eventually leaving a job. In addition, about four percent of work time and millions of dollars are lost each year due to burnout $(5,6)$. Health sector workforce due to exposure to multiple stressors (psychological, emotional, physical, managerial and Interpersonal) are more prone to experience higher levels of burnout than other workers $(4,7-9)$. In addition, among health sector workers, females nurse are most susceptible to burnout, which is a concern due to some reasons. Firstly, the highest percentage of health sector workforce is related to nurses dealing with patients at the front line (10). Secondly, job satisfaction and burnout are strongly associated with turnover nurses, which would lead to a shortage of nurses (11). Thirdly and the most important, lack of nurses is significantly associated with medical errors, inadequate health care and poor outcomes for patients (12-14). Previous studies have shown that social capital has an impact on burnout (1517). At the time of this study, no study has been published in Iran investigating the association between other types of capital (economic and cultural) and burnout. However, it seems that the types of capital are effective on social relationship, values, attitudes and opinions of individuals. Pierre Bourdieu, a French sociologist, indicated that capital is divided into three types of social, economic and cultural ones. He believed it is the capital that allows individual to monitor its fate and others. In general, according to the Bourdieu's view, the concept of economic capital originates from economic zone. Cultural capital includes various types of self- knowledge derived from the dignity of individual. Besides, social capital includes 
Karami Matin B et al.

social relationships among individuals (18). Burnout, as a consequence of job stress is more common among nurses than other workers in the health sector. Studies have shown that burnout among nurses in Iran is higher than other countries (19). In comparison with male nurses, female nurses undergo a lot of stress and pressure and are more susceptible to burnout due to simultaneous activities in hospital and training children at home.

\section{Objectives}

Therefore, this study had two objectives. Firstly, the prevalence of burnout was investigated among nurses in educational hospitals of Kermanshah University of Medical Sciences; secondly, the impact of capital types (social, cultural and economic) on burnout was also studied.

\section{Patients and Methods}

This was a descriptive cross-sectional study. The study population included all female nurses working in educational hospitals of Kermanshah University of Medical Sciences in 2012. In total, 385 of female nurses working in seven hospitals (Imam Khomeini, Imam Reza, Farabi, Imam Ali, Muhammad Kermanshahi, Moatazedi and Talaghani) were studied. First, the sample size was determined for each hospital according to each hospital data regarding the number of its female nurses, then questionnaires were distributed randomly among female nurses at each hospital. A questionnaire containing three parts was used for data collection. The first part was the Maslach Burnout Inventory (MBI) originally designed by Maslach and Jackson in 1981 (20). MBI contains 22 items about three subscales of EE (nine items), DP (eight items) and PA (five items). These items are ranked from zero (never) to six (every day). In the EE subscale, scores of $>26$ indicate high $\mathrm{EE}$, whereas scores of 17-26 indicate moderate and scores of $<17$ as a low degree of EE. In the DP subscale, scores of $>12$ indicate high DP, whereas scores of 7-12 indicate moderate and scores of $<7$ as a low degree of DP. Besides, regarding the subscale of PA, scores of $>39$ indicate high PA, whereas scores of 32-38 indicate moderate and scores of $<32$ as a low degree of PA. The second part of the questionnaire was about types of capital (economic, social and cultural), which its reliability and validity were approved in the previous study (21). There were 15 items on social capital. Scores of $>35$ indicate high social capital, whereas scores of 25-35 indicate moderate and scores of $<25$ as a low degree of social capital. To measure cultural capital, four items were asked. Scores of $>14$ indicate high cultural capital, whereas scores of 7-14 indicate moderate and scores of $<7$ as a low degree of cultural capital. Economic capital was measured by monthly per capita expenditure. Scores of $>15000000$ IRR indicate high economic capital, whereas scores of 7500000-15000000 IRR indicate moderate and scores of $<7500000$ IRR as a low degree of economic capital. The third part of the questionnaire was demographic characteristics including work experience, work shifts and other factors. Data Analysis was done by using SPSS version 18 (Chicago: SPSS Inc).

\section{Results}

The mean and median age of the subjects were 30.3 and 30 years, respectively (SD $=3.65)$. Three hundred and nineteen were in the age range of $25-34$ years ( $82.9 \%)$. One hundred and eighty six were married (48.2\%), whereas 180 were single (46\%) and 19 were divorced (5\%). Our study showed that the average expenditure per month for $2.3 \%$ of respondents had a less than 7500000 Iranian Rials (IRR), 83.6\% between 7500000 and 15000000 IRR, and $14 \%$ had more than 15000000 IRR. Most of the study population had a bachelor's degree (76\%) and almost 5\% had a master of sciences or higher degrees. One hundred and seventy two had a work experience between 5 and 10 years (44.8\%), whereas 124 had work experiences more than 10 years (32.1\%) and $23.1 \%$ had work experiences less than 5 years. Two hundred and eighty two had rotation working shifts (74.3\%) and the rest had fixed working shifts. The study results regarding the capital types (cultural, economic and social) are shown in Table 1. Our study showed that 108 female nurses had a low cultural capital and only 46 had a high cultural capital (11\%).

Furthermore, 190 of female nurses had a high social capital (almost $50 \%$ ), whereas 45 had a low social capital (12\%). Regarding the economic capital, $83.6 \%$ of female nurses had a moderate economic capital. The prevalence of burnout and its subscales for the study population is shown in Table 3. In general, $40.2 \%$ of subjects had high burnout, based on high EE, high DP and low PA.

The mean burnout score in our study population was 42.3. The mean scores for EE, DP and PA were 33.7, 16 and 25.7 , respectively. About $62 \%, 58 \%$ and $68 \%$ of female nurses had a high level of DP, high EE and low PA, respectively.

Table 1. Distribution of Cultural, Economic and Social Capital Among Female Nurses in Educational Hospitals of Kermanshah, Western Iran ${ }^{\mathrm{a}}$

\begin{tabular}{lccc}
\hline & Cultural & Social & Economic \\
\hline Low capital & $108(27)$ & $45(12)$ & $53(14)$ \\
Moderate capital & $231(60)$ & $150(39)$ & $322(83.6)$ \\
High capital & $46(12)$ & $190(49.3)$ & $10(2.4)$ \\
\hline
\end{tabular}

$\mathrm{a}$ Data are presented as No. (\%)

Table 2. Prevalence of Burnout and its Three Subscales Among Female Nurses in Educational Hospitals of Kermanshah, Western Iran $^{\mathrm{a}}$

\begin{tabular}{lcccc}
\hline Dimension & EE & DP & PA & Burnout \\
\hline Low & $30(7.8)$ & $40(10.3)$ & $260(67.5)$ & $99(25.8)$ \\
Mean & $130(34)$ & $105(27.3)$ & $90(23.4)$ & $131(34)$ \\
High & $225(58.2)$ & $240(62.4)$ & $35(9.1)$ & $155(40.2)$ \\
\hline
\end{tabular}

a Abbreviations: DP, depersonalization; EE, emotional exhaustion; PA, personal accomplishment. 
Table 3. Correlation Between Burnout and Types of Capital and Sociodemographic Factors Among Female Nurses in Educational Hospitals of Kermanshah, Western Iran ${ }^{\mathrm{a}}$

\begin{tabular}{lccc}
\hline & R & P Value & $\begin{array}{c}\text { Correlation } \\
\text { With Burnout }\end{array}$ \\
\hline Cultural capital & -0.21 & 0.01 & Yes \\
Social capital & -0.34 & 0.055 & Yes \\
\hline Economic capital & -0.057 & 0.001 & Yes \\
Age & 0.17 & 0.16 & No \\
Marital status & 6.4 & $<0.001$ & Yes \\
Work experience & -0.1 & 0.043 & Yes \\
Working shift & 4.5 & $<0.001$ & Yes \\
\hline Education & 0.07 & 0.4 & No \\
\hline
\end{tabular}

a Abbreviation: R, Pearson Correlation.

Besides, $7.8 \%, 10.3 \%$ and $67.5 \%$ of subjects reported low EE, DP and PA respectively. There was a significant positive correlation between burnout and social capital ( $\mathrm{P} \leq$ 0.05 ), economic capital ( $\mathrm{P} \leq 0.001)$ and cultural capital $(P \leq 0.01)$. The correlation between burnout and capital types and sociodemographic factors (age, marital status, work experience and working shift) is shown in Table 3.

In addition, there was a significant correlation between burnout and marital status, working shift and work experience; but there was no correlation between burnout and age (Table 3 ).

\section{Discussion}

Burnout is one of the consequences of stressful job able to decrease productivity and quality of performance, and even job turnover. The prevalence of burnout in health working workers is higher than other sectors. Therefore, the aim of this study was to evaluate the prevalence of burnout among female nurses working in educational hospitals of Kermanshah University of Medical Sciences and its association with capital types (economic, cultural and social). The mean scores of EE, DP, and PA were 33.68, 15.95 , and 25.66, respectively. Besides, about $62 \%, 58 \%$ and $68 \%$ of female nurses had a high level of DP, high EE and low PA, respectively which is consistent with other studies $(13,15)$. The present study showed high levels in the two subscales of EE and DD, and low level in one subscale of PA among female nurses, which is consistent with other studies $(15,22,23)$. The mean score and prevalence of burnout were $42.3 \%$ and $40 \%$, respectively. Khammarnia et al. founded that the prevalence of burnout among female nurses was high (15). The mean score of burnout was found to be 40.84 in the study performed by Momeni et al. among nurses working in Arak University of Medical Sciences (24). Richard and Peter concluded that about $50 \%$ of nurses reported high level of burnout (25). Our study showed that approximately 50\% of subjects had a high social capital, $60 \%$ had a moderate cultural capital and $83 \%$ had a moderate economic capital. More- over, there were positive correlations between types of capital (cultural, social and economic) and burnout. On the other hands, when the social, cultural and economic capital is increasing, burnout decreases, which is consistent with some previous investigations $(13,15,26)$. In addition, Khodabakhsh et al. found a negative correlation between economic and social conditions and burnout (26). The current study showed that there was a positive correlation between burnout and marital status; on the other hands, burnout among married females was higher than unmarried ones. This is similar to recent studies published in Tehran (27), Spain (28) and Taiwan (29). Although, there was no correlation (positive or negative) between burnout and marital status in some studies (30, 31). This study showed that there was a positive correlation between burnout and work experience. On the other hands, when the work experience is increased, burnout decreases, which is similar to previous studies $(24,32,33)$. These results could be due to two reasons. Firstly, female nurses with more work experience can more easily overcome with stress of their workplace; and secondly, they can better manage their work and have more capability with stresses and difficulties in hospital environments. In addition, people with none of these capabilities are forced to change their job. Furthermore, there was no significant correlation between burnout and age, which had been indicated in other studies (27). This study had two limitations. First, based on other studies, other factors such as employment status might also contribute to burnout, which was not investigated in this study. Second, it is likely that the type of hospital (private, public, educational and charities) has an effect on burnout which was not possible to examine in this study, and it is suggested to consider it in further investigations. This study revealed a high level of burnout among female nurses working in educational hospitals in Kermanshah University of Medical Sciences. Not only the type of (economic, cultural and social) capital has an impact on burnout, but also other factors including work experience and marital status might have the same impact. The following recommendations could be effective to reduce the prevalence of burnout among female nurses:

Improving cultural capital of hospital staff and particularly nurses, Increasing income level and workplace safety,Forming informal groups between nurses, Holding consultation meetings and introducing methods for anxiety management.

\section{Acknowledgements}

We would like to appreciate all nurses who participated in this study and, Mrs. Mirzaei who helped us in data collection.

\section{Authors' Contributions}

Behzad Karami Matin, supervised the study; Satar Rezaei and Nafe Babasafari, designed methods and wrote the ar- 
ticle; Sina Ahmadi and Sayed Fahim Irandoost, collected and analyzed data.

\section{Funding/Support}

This paper was the result of a research project conducted in educational hospitals in Kermanshah and supported by Kermanshah University of Medical Sciences.

\section{References}

1. American Psychological Association. Overwhelmed by Workplace Stress? You're Not Alone. Washington: APA; 2012. Available from http://www.apa.org/helpcenter/work-stress.aspx.

2. Malach-Pines A. Nurses' burnout: an existential psychodynamic perspective. J Psychosoc Nurs Ment Health Serv. 2000;38(2):23-31.

3. Freudenberger HJ. Staff burn-out. J Soc Issues .1974;30(1):159-65.

4. Ahola K, Kivimaki M, Honkonen T, Virtanen M, Koskinen S, Vahtera J, et al. Occupational burnout and medically certified sickness absence: a population-based study of Finnish employees. J Psychosom Res. 2008;64(2):185-93.

5. Demir A, Ulusoy M, Ulusoy MF. Investigation of factors influenc ing burnout levels in the professional and private lives of nurses. Int J Nurs Stud. 2003;40(8):807-27.

6. Sahebazzamani M, Safavi M, Farahani H. [Burnout of nursesemployed at Tehran psychiatric hospitals and its relation withsocia supports]. Med Sci J Islamic Azad Univ. 2009;19(3):206-11.

7. Sahraian A, Fazelzadeh A, Mehdizadeh AR, Toobaee SH. Burnout in hospital nurses: a comparison of internal, surgery, psychiatry and burns wards. Int Nurs Rev. 2008;55(1):62-7.

8. Wachter RM. The state of hospital medicine in 2008. Med Clin North Am. 2008;92(2):265-73.

9. Glasberg AL, Norberg A, Soderberg A. Sources of burnout among healthcare employees as perceived by managers. I Adv Nurs. 2007;60(1):10-9.

10. Bureau of Labor Statistics. Occupational Outlook Handbook Healthcare Registered Nurses. 2010. Available from: http:/|www.bls.gov| ooh/healthcare/registered-nurses.htm.

11. Buchan J, Aiken L. Solving nursing shortages: a common priority. JClin Nurs. 2008;17(24):3262-8.

12. Hugonnet S, Chevrolet IC, Pittet D. The effect of workload on infection risk in critically ill patients. Crit Care Med. 2007; 35(1):76-81.

13. Stone PW, Mooney-Kane C, Larson EL, Horan T, Glance LG, Zwanziger J, et al. Nurse working conditions and patient safety outcomes. Med Care. 2007;45(6):571-8.

14. Kane RL, Shamliyan TA, Mueller C, Duval S, Wilt TJ. The association of registered nurse staffing levels and patient outcomes: system atic review and meta-analysis. Med Care. 2007;45(12):1195-204.

15. Khammarnia M, Tourani S, Mohammadi R. [The effect of social capital dimensions on burnout in female nurses]. Bimonthly $\mathrm{J}$
Hormozgan Univ Med Sci. 2011;15(3):209-17.

16. Vaziri Rad V. Investigate the relationship between social capital and development of organizational learning capacity MSc. Tehran: Tehran University; 2008

17. Gächter M, Savage D, Torgler B. The Relationship between Stress and Social Capital among Police Officers. School of Economics and Finance. Discussion Papers and Working Papers Series. 2009.

18. Rob S. [Great thinkers of sociology].Tehran: Nasher Publisher; 2004.

19. Sheikhi MR, Sareechloo ME, Javadi A, Moradi M. [Effect of nurses empowerment on coping with job stresses].JQazvin Univ Med Sci. 2009;12(4):38-42.

20. Maslach C, Jackson SE, Leiter MP. Maslach Burnout Inventory Manual. 3th ed: Consulting Psychologists Press; 1996.

21. Ahmadi S. The effect types of capital (economy, cultural and social) family in parent attitude to gender discrimination. Tehran: Tehran University; 2012.

22. Rahimi A, Ahmadi F, Akhond MR. [An investigation of amount and factors affecting nurses' job stress in some hospitals in Tehran]. Hayat. 2004;10(3):13-22.

23. Delpasand M, Raeissi P, Begdeli F, Shahabi M. The impact of job rotation on nurses burnout in Ayatollah Kashani hospital, Tehran: A case study. Iran Occup Health. 2011;7(4):78-87.

24. Momeni H, Salehi A, Seraji A. [Comparing burnout among nurse in the Treatment and Education of Medical Sciences]. Arak Univ Med Sci.2008;12(4):113-23.

25. Richard J, Peter E. Nursing and health care management and policy. Int J Nurs Stud. 2004;48(6):622-30.

26. Khodabakhsh MR, Mansuri P. Analysis and comparison between frequency and depth of job-burnout aspects among male and female nurses. Zahedan J Res Med Sci. 2011;13(4):40-2.

27. Rashedi V, Foroughan M, Hosseini MA. Burnout and related demographic variables among Tehran Welfare Organization staffs. J Kermanshah Univ Med Sci. 2012;16(1):28-36.

28. Losa Iglesias ME, Becerro de Bengoa Vallejo R, Salvadores Fuentes $P$. The relationship between experiential avoidance and burnout syndrome in critical care nurses: a cross-sectional questionnaire survey. Int J Nurs Stud. 2010;47(1):30-7.

29. Yeh WY, Cheng Y, Chen CJ. Social patterns of pay systems and their associations with psychosocial job characteristics and burnout among paid employees in Taiwan. Soc Sci Med.2009;68(8):1407-15.

30. Akkasheh G. [Prevalence of burnout in senior medical students of Kashan University of medical sciences in 2008]. Qom Univ Med Sci J. 2012;4(3):37-41.

31. Taee M, Safizadeh H, Divsalar K. Frequency of burnout among general practitioners of kerman city, 2008. J Kerman Univ Med Sci. 2010;17(3):268-76.

32. Saberi H, Moravaji A, Sadafi M. Burnout assessment and effective factors on the manager of Kashan industry. Iran Occup Health 2008;5(3):60-7.

33. Yousefy AR, Ghassemi GhR. Job burnout in psychiatric and medical nurses in Isfahan, Islamic Republic of Iran. East Mediter Health J. 2006;12(5):662. 